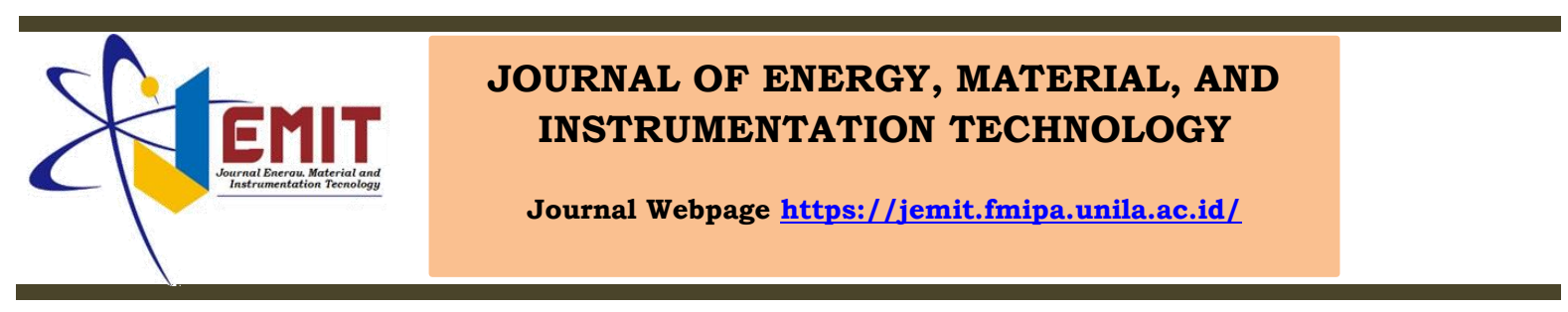

\title{
Perhitungan Burn Up pada Reaktor HCLWR Model Geometri Heksagonal Dua Dimensi BahanBakar Uranium menggunakan SRAC COREBN
}

\author{
Wahyuning Ramadhanta Ardantia, Yanti Yulianti ${ }^{\mathrm{b}}$, Agus Riyanto ${ }^{c}$, dan Syafriadi \\ Jurusan Fisika, Universitas Lampung, Bandar Lampung, Indonesia, 35141
}

\begin{tabular}{|c|c|}
\hline Article Information & Abstract \\
\hline $\begin{array}{l}\text { Article history: } \\
\text { Received } 06 \text { Maret } 2020 \\
\text { Received in revised form } 06 \\
\text { Maret } 2020 \\
\text { Accepted } 10 \text { Maret } 2020 \\
\text { Keywords: burn up, } \\
\text { COREBN, convertion ratio, } \\
\text { keff. }\end{array}$ & $\begin{array}{l}\text { This study about burn up calculations on the HCLWR reactor with two dimensional } \\
\text { hexagonal geometric models of uranium using SRAC COREBN has been carried. } \\
\text { This study used uranium-235 and uranium-238 as the fuels, light water as coolant } \\
\text { and moderator. The calculation was done with computational simulation of } \\
\text { COREBN. The calculation aims to produce a conversion ratio more than } 1 \text { and a } \\
\text { critical multiplication factor (keff). The research used fuels enrichment, burn up } \\
\text { period, burn up step, linier power and volume fraction parameters. The percentage } \\
\text { of enrichment from U1 and U3 were } 3 \% \text { and U2 was } 2,5 \% \text {. The volume fraction of } \\
\text { each material was } 52 \% \text { fuels, } 12 \% \text { cladding, and } 36 \% \text { coolant, the reactor operating } \\
\text { period for } 548 \text { days with } 6 \text { step of burn up then the reactorpower is } 2400 \mathrm{MW} \text { and } \\
\text { the linear poweris } 1,792722 \mathrm{MW} \mathrm{cm} \text {. The calculation of conversion ratio was } \\
1,01233 \text { and keff was } 0,901 \text {. }\end{array}$ \\
\hline
\end{tabular}

\section{Informasi Artikel}

Proses artikel:

Diterima 06 Maret 2020

Diterima dan direvisi dari

06 Maret 2020

Accepted 10 Maret 2020

Kata kunci: burn up, COREBN, rasio konversi, keff

\section{Pendahuluan}

Pembangkit Listrik Tenaga Nuklir (PLTN) adalah salah satu pembangkit energi alternatif yang sekarang sudah banyak digunakan di berbagai negara maju, seperti Amerika Serikat, Prancis, jerman Jepang dan negara maju lainnya. PLTN digunakan untuk membangkitkan tenaga listrik yang realtif murah, aman dan tidak mencemari lingkungan. PLTN memanfaatkan energi reaktor nuklir sebagai sumber energi listrik. PLTN menggunakan satu atau beberapa reaktor nuklir sebagai sumber panasnya yang dimanfaatkan untuk pembangkit daya termal (BATAN, 2019).

Reaktor nuklir adalah tempat berlangsungnya reaksi nuklir (Adiwardojo, dkk., 2010). Uranium merupakan salah satu bahan bakar yang sering digunakan. Di Indonesia memiliki cadangan uranium sebanyak 70.000 ton (Bastori dan Moch, 2017). Perkembangan reaktor nuklir dari generasi ke generasi terus mengalami perubahan dari segi efektifitas biaya, keselamatan, siklus bahan bakar dan komersialisasi. HCLWR merupakan salah satu jenis

\begin{abstract}
Abstrak
Telah dilakukan penelitian tentang perhitungan burn up pada reaktor HCLWR model geometri heksagonal dua dimensi bahan bakar uranium menggunakan SRAC COREBN. Penelitian ini menggunakkan bahan bakar adalah uranium-235 dan uranium-238, sedangkan air ringan digunakan sebagai pendingin dan moderator. Perhitungan dilakukan dengan simulasi komputasi menggunakan kode COREBN yang terdapat pada program SRAC. Tujuan dari perhitungan burn up dilakukan untuk menghasilkan nilai rasio konversi lebih dari 1 dan nilai keff yang ptimal. Parameter yang digunakan pada penelitian ini adalah pengayaan bahan bakar, periode burn up, step burn up, daya linier serta fraksi volume. Pengayaan
yang didapat pada U1 dan U3 sebesar 3\% serta U2 sebesar 2,5\% dengan fraksi volume dari masing-masing material yaitu $52 \%$ bahan bakar, $12 \%$ selongsong dan $36 \%$ moderator. Sehingga reaktor dapat menyala hingga akhir periode selama 548 hari dengan 6 step burn up dan menghasilkan daya sebesar $2.400 \mathrm{MW}$, daya linier sebesar 1,792722 MW/cm, nilai rasio konversi 1,01233 dan keff sebesar 0,901.
\end{abstract}


Ardanti W R, Yulianti Y, Riyanto A, dan Syafriadi, 2020. Perhitungan Burn Up pada Reaktor HCLWR Model Geometri Heksagonal Dua Dimensi BahanBakar Uranium menggunakan SRAC COREBN, Journal of Energy Material and Instrumentation Technology, Vol. 1 No. 1,2020

reaktor hasil pengembangan dari reaktor generasi I yaitu LWR. HCLWR mulai dikembangkan oleh JAERI (Japan Atomic Energy Research Institute) pada tahun 1985 dengan desain konseptual. HCLWR didesain dengan tujuan untuk mencapai rasio konversi tinggi, jaminan keselamatan (setara atau lebih tinggi dari tingkat keselamatan LWR), dan memiliki nilai eknonomi yang tinggi (Sugimoto., dkk, 1989). HCLWR dengan kisi pitch yang lebih padat memiliki kelebihan dua fitur desain dibandingkan dengan LWR konvensional yaitu mengurangi rasio volume air terhadap bahan bakar dan pengayaan fisil plutonium yang lebih tinggi (Ishiguro, 1989). HCLWR menggunakan pendingin berupa air ringan $\left(\mathrm{H}_{2} \mathrm{O}\right)$. HCLWR memiliki beberapa komponen penting, salah satunya yaitu teras (inti) reaktor.

Teras (inti) reaktor merupakan salah satu bagian yang penting dari reaktor nuklir (Dudeerstadt dan Louis, 1976). Desain inti reaktor menjadi tahap awal dan salah satu bagian penting dalam reaktor nuklir agar menghasilkan sistem PLTN yang aman, efektif dan ekonomis pada waktu operasi. Parameter yang menentukan aman tidaknya reaktor tersebut beroperasi selama periode tertentu disebut reaktivitas reaktor. Selain itu, proses perancangan desain inti reaktor memerlukan analisis detail, lengkap dan berkelanjutan (Nurul, dkk., 2015). Analisis yang dapat dilakukan pada inti reaktor yaitu menganalisis burn up inti reaktor. Kedua parameter ini memiliki hubungan dengan periode operasi reaktor. Reaktivitas reaktor akan menghasilkan daya yang konstan dan nilainya optimal ketika bernilai mendekati satu selama periode operasi.

Analisis perhitungan burn up inti teras reaktor perlu dilakukan untuk mengetahui pembakaran yang ada di inti reaktor melalui nilai rasio konversi seketika (instantaneous conversion ratio). Rasio konversi didefinisikan sebagai rasio antara laju pembentukan isotop fisil baru dengan laju destruksi isotop fisil. Jika laju ini bernilai lebih dari satu, maka nilai rasionya disebut dengan rasio pembiakan (breeding ratio) (Agung, 2017). Nilai rasio konversi yang besar dibutuhkan agar akses reaktivitas yang dicapai cukup rendah selama nwaktu burn up yang panjang (Subekhi,dkk., 2015) dan panjang rasio konversi lebih dari 1 menunjukan bahwa bahan bakar yang dikonsumsi lebih sedikit daripada bahan bakar yang diproduksi.

\section{Metode Penelitian}

Alat dan bahan yang digunakan dalam penelitian ini adalahseperangkat komputer dengan Operating System Linux Mint 18.1 dan SRAC-COREBN. Langkah-langkah penelitian yang akan dilakukan sebagai berikut.

\subsection{Menentukan Pengayaan}

Perangkat bahan bakar terdiri dari tiga komposisi yaitu daerah bahan bakar pertama, daerah bahan bakar kedua, dan daerah bahan bakar ketiga. Masing-masing daerah akan dilakukan pengayaan sebesar $2 \%-4 \%$ dengan jarak $0,5 \%$.

\subsection{Menghitung Densitas Atom}

Setiap komponen pada reaktor seperti bahan bakar (fuel), kelongsong (cladding), dan pendingin (moderator) dihitung densitas atomnya untuk digunakan sebagai input pada PIJ. PIJ adalah salah satu kode pada SRAC yang digunakan untuk melakukan perhitungan neutronik tingkat sel. Perhitungan pada PIJ digunakan untuk menghomogenisasi energi neutron. Rumus untuk menghitung densitas atom ditunjukkan pada persamaan 1.

$$
\begin{gathered}
N=\frac{\rho N_{A}}{M} \\
\text { dengan, } \\
N=\text { densitas atom }\left(\text { atom } / \mathrm{cm}^{3}\right) \\
\rho=\text { massa jenis }\left(\mathrm{g} / \mathrm{cm}^{3}\right) \\
N_{A}=\text { bilangan Avogadro }\left(0,6022 \times 10^{24} \text { atom } / \mathrm{mol}\right) \\
M=\text { massa molekul }(\mathrm{g} / \mathrm{mol})
\end{gathered}
$$

\subsection{Melakukan Perhitungan pada PIJ}

Perhitungan pada PIJ dilakukan untuk menentukan geometri tingkat sel. Geometri sel yang akan digunakan berbentuk silinder satu dimensi melingkar. 1, 2, 3 merupakan bahan bakar 4 merupakan kelongsong, dan 5, 6 merupakan pendingin. Hasil dari perhitungan tingkat sel akan disimpan dalam file MACRO, file ini akan digunakan sebagai input pada HIST untuk meregistrasi material yang digunakan pada COREBN. Bentuk geometri selnya ditunjukkan seperti pada Gambar 1.

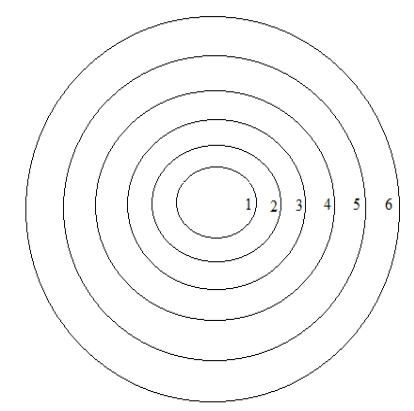

Gambar 1. Model Geometri Silinder 1D Melingkar 


\subsection{Menginput Data pada HIST}

HIST adalah history file. Pekerjaan yang dilakukan oleh HIST seperti menentukan geometri teras dan registrasi material, menentukan jenis elemen bahan bakar, menentukan jenis elemen non bahan bakar, dan melakukan pemuatan elemen bahan bakar.

\subsection{Melakukan Perhitungan pada COREBN}

COREBN adalah kode tambahan pada SRAC yang digunakan untuk menghitung burn up pada tingkat teras (inti). Input pada COREBN berhubungan dengan kondisi operasi seperti daya termal, periode operasi, pola pemuatan elemen bahan bakar, dan pola pemuatan elemen kendali (Okimura, 2007). Geometri teras reaktor yang akan digunakan berbentuk silinder 2 dimensi dengan perhitungan 1/6 bagian teras reaktor seperti yang ditunjukkan pada Gambar 2.

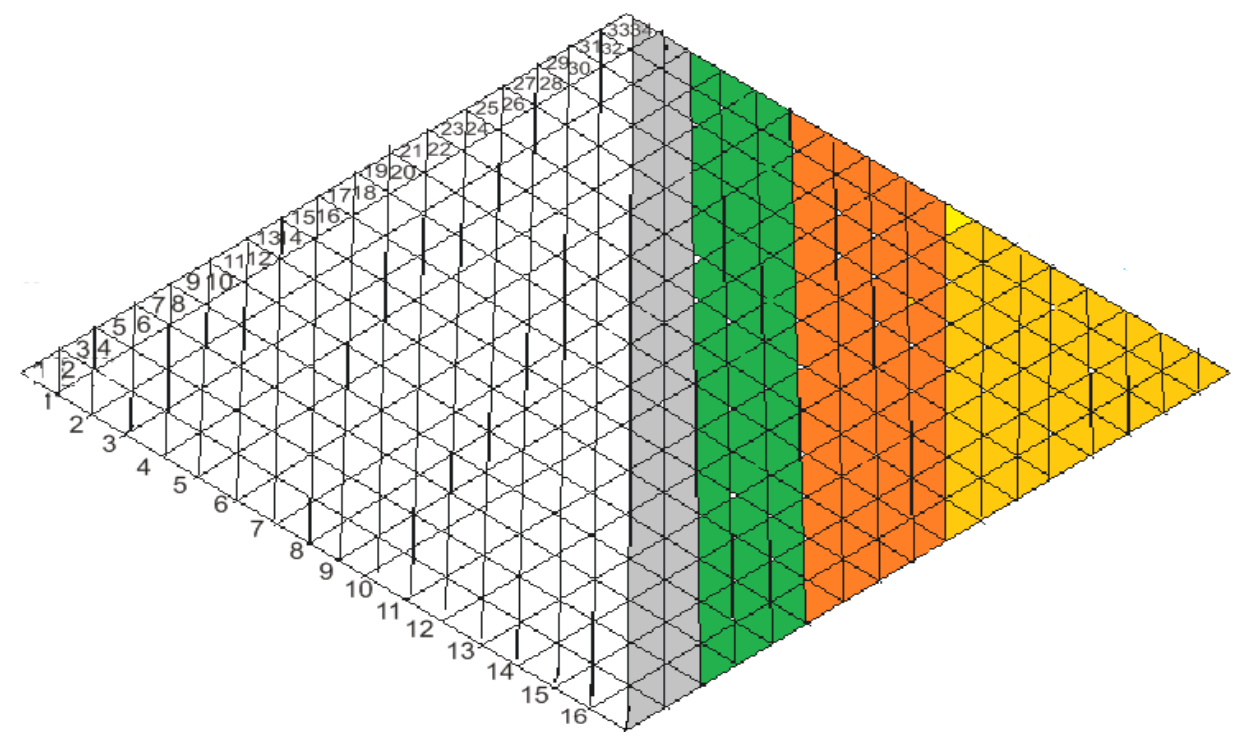

Gambar 2. Desain konfigurasi $1 / 6$ bagian permukaan teras reaktor

\section{Hasil dan Pembahasan}

\subsection{Variasi Pengayaan Bahan Bakar}

Pengayaan dilakukan untuk memperkaya jumlah persentase isotop U235 dalam bahan bakar. Hasil dari variasi pengayaan di ketiga daerah bahan bakar ditunjukkan pada Gambar 3. Gambar 3 menunjukkan semakin besar pengayaan yang diberikan kepada bahan bakar $\mathrm{U}^{235}$, maka nilai $k_{\text {eff }}$ akan semakin meningkat. Hal ini menunjukkan telah terjadi reaksi fisi. Semakin besar pengayaan bahan bakar, maka reaksi fisi juga semakin besar karena jumlah neutron yang dihasilkan semakin meningkat.

\subsection{Penambahan Periode Burn Up}

Burn up (derajat bakar) digunakan untuk menyatakan jumlah bahan bakar yang terbakar atau melakukan reaksi fisi. Hasil dari penambahan periode burn up ditunjukkan pada Tabel 1 yang menunjukkan nilai $k_{\text {eff }}$ dan rasio konversi setelah penambahan periode burn up. Hasil yang diperoleh menunjukkan bahwa semakin lama proses pembakaran, maka nilai $k_{\text {eff }}$ akan semakin kecil seiring dengan peningkatan nilai rasio konversi. Hal ini menunjukkan bahwa konsumsi bahan bakar fisil memiliki rasio yang lebih rendah dibandingkan periode awal teras reaktor, sehingga bahan bakar fisil tersebut tidak mampu untuk menyediakan neutron yang cukup dan mengakibatkan teras menjadi kritis ataupun superkritis. Ketika nilai rasio konversi yang dihasilkan cukup baik, teras reaktor akan berada dalam keadaan subkritis (Ardiansyah, 2018). Faktor lain yang mengakibatkan nilai $k_{\text {eff }}$ semakin menurun seiring dengan bertambahnya waktu operasi yaitu berkurangnya densitas nuklida fisil dan fertil yang ada di dalam teras reaktor (Permata dan Handayani, 2016). 
Ardanti W R, Yulianti Y, Riyanto A, dan Syafriadi, 2020. Perhitungan Burn Up pada Reaktor HCLWR Model Geometri Heksagonal Dua Dimensi BahanBakar Uranium menggunakan SRAC COREBN, Journal of Energy Material and Instrumentation Technology, Vol. 1 No. 1,2020

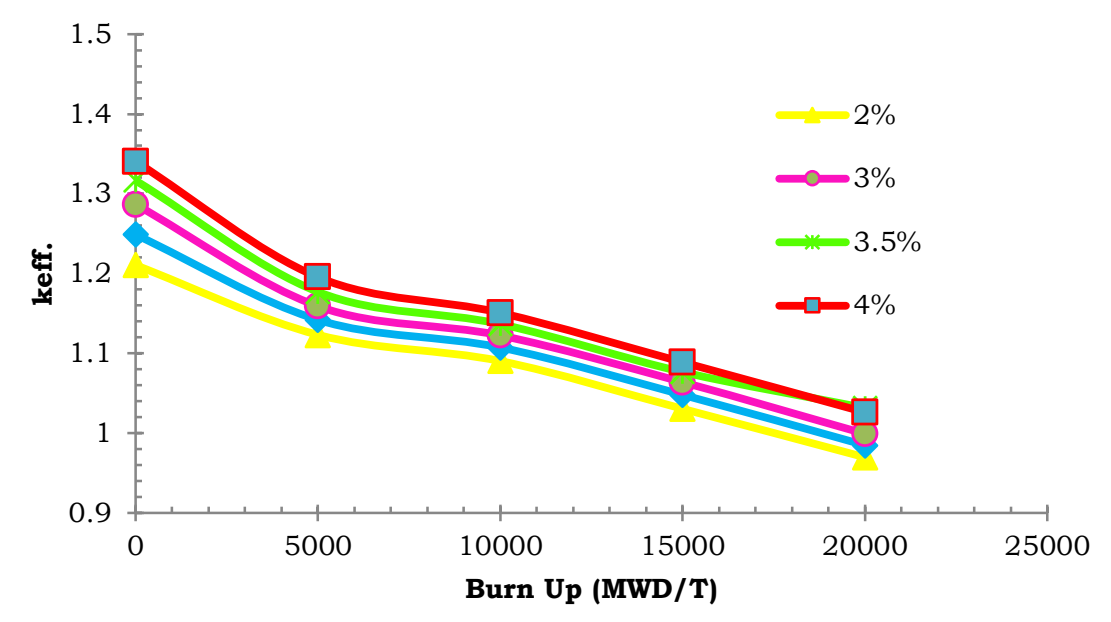

(a)

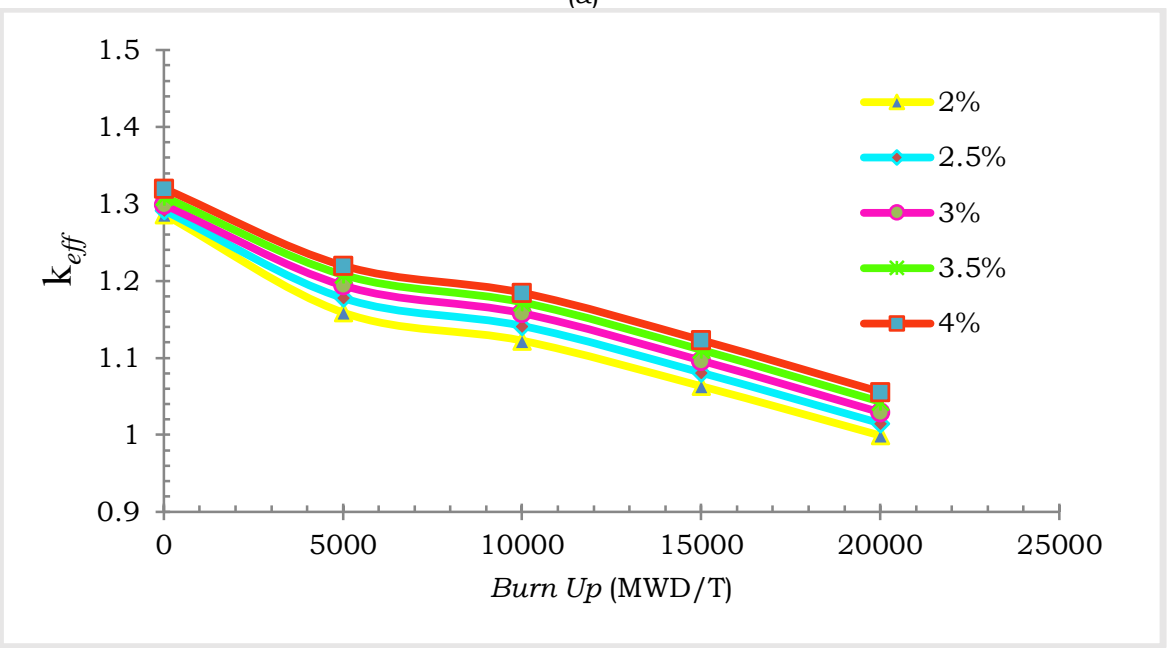

(b)

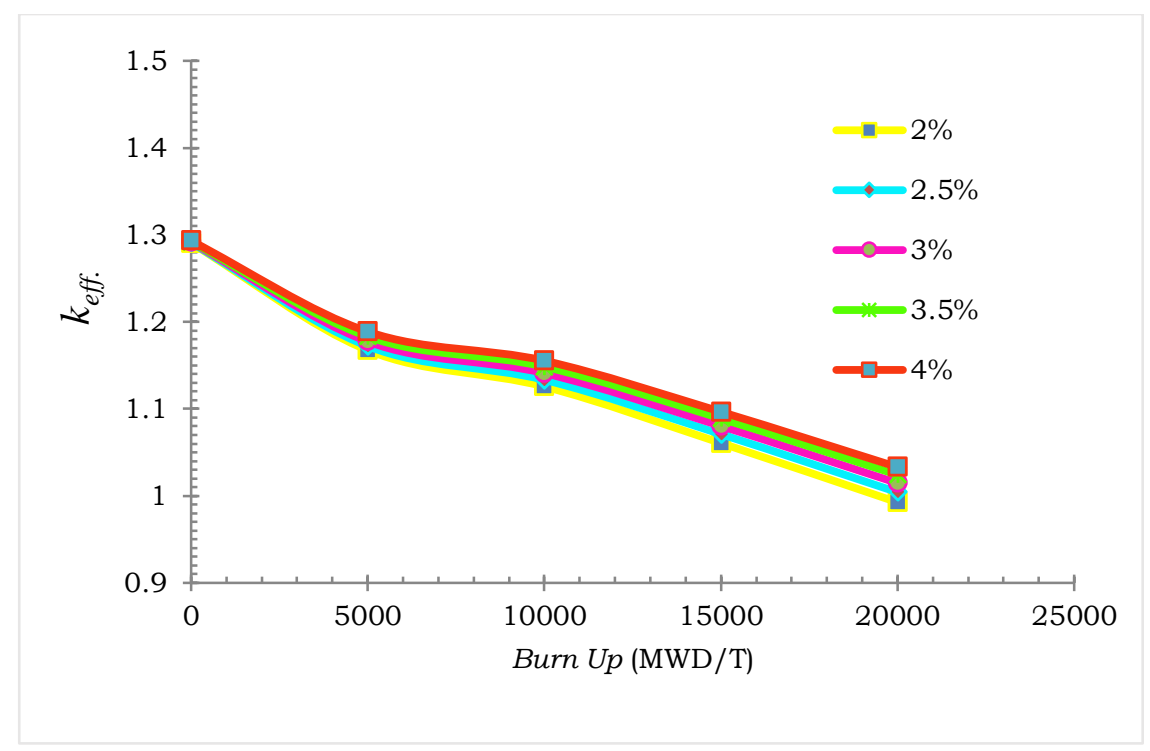

(c)

Gambar 3. Pengaruh pengayaan bahan bakar terhadap nilai $k_{\text {eff }}$ (a) Daerah pertama; (b) Daerah kedua; (c) Daerah ketiga

Tabel 1. Pengaruh penambahan periode burn up terhadap nilai $k_{\text {eff }}$ dan nilai rasio konversi 
Ardanti dkk, 2020/ J. Energy Mater. Instrum. Technol. Vol. 1 No. 1, 2020

\begin{tabular}{|c|c|c|c|c|c|c|}
\hline \multirow{3}{*}{$\begin{array}{c}\text { Step } \\
\text { burn up }\end{array}$} & \multicolumn{6}{|c|}{ Periode Burn Up (Hari) } \\
\hline & 182 & & & & 912 & \\
\hline & $k_{\text {eff }}$ & $\begin{array}{c}\text { Rasio } \\
\text { konversi }\end{array}$ & $k_{e f f}$ & $\begin{array}{c}\text { Rasio } \\
\text { konversi }\end{array}$ & $k_{\text {eff }}$ & $\begin{array}{c}\text { Rasio } \\
\text { konversi }\end{array}$ \\
\hline 1 & 1,291 & 0,489 & 1,291 & 0,489 & 1,291 & 0,489 \\
\hline 2 & 1,177 & 0,524 & 1,177 & 0,524 & 1,177 & 0,524 \\
\hline 3 & 1,134 & 0,551 & 1,094 & 0,583 & 1,030 & 0,641 \\
\hline 4 & 1,103 & 0,576 & 1,008 & 0,668 & 0,921 & 0,771 \\
\hline 5 & 1,091 & 0,588 & 0,933 & 0,755 & 0,838 & 0,864 \\
\hline
\end{tabular}

\subsection{Variasi Daya Linear}

Perubahan daya linear dapat ditentukan dengan mengubah daya yang ada pada reaktor. Berdasarkan penelitian yang telah dilakukan sebelumnya, semakin besar nilai daya linear maka nilai $k_{\text {eff }}$ akan semakin kecil (Antartika, 2017). Hasil dari variasi daya linear terhadap nilai $k_{\text {eff }}$ dan rasio konversi bertutur-turut ditunjukkan pada Tabel 2 dan Tabel 3. Berdasarkan Tabel 2 dan Tabel 3 diperoleh bahwa semakin bertambah nilai daya linear, maka nilai $k_{\text {eff }}$ akan berkurang. Penurunan nilai $k_{\text {eff }}$ akan menyebabkan nilai rasio konversi meningkat. Perubahan daya linear belum memberikan perubahan yang signifikan terhadap nilai rasio konversi. Rasio konversi paling tinggi yang dapat dicapai yaitu 0,692345 dengan $k_{\text {eff }} 0,987$ pada daya linear sebesar $1,868 \mathrm{MW} / \mathrm{cm}$.

Tabel 2. Hasil Nilai $k_{\text {eff }}$ Setelah Perubahan Daya Linear

\begin{tabular}{lccccccc}
\hline \multirow{2}{*}{$\begin{array}{c}\text { Daya linear } \\
(\mathrm{MW} / \mathrm{cm})\end{array}$} & $\begin{array}{c}\text { Daya } \\
(\mathrm{MW})\end{array}$ & \multicolumn{7}{c}{ Faktor Multiplikasi $\left(k_{\text {eff }}\right)$} \\
\cline { 3 - 8 } & & 1 & 2 & 3 & 4 & 5 & 6 \\
\hline 1,494 & 2000 & 1,291 & 1,974 & 1,112 & 1,112 & 1,079 & 1,022 \\
1,569 & 2100 & 1,291 & 1,195 & 1,107 & 1,107 & 1,073 & 1,014 \\
1,644 & 2200 & 1,291 & 1,194 & 1,103 & 1,103 & 1,061 & 1,010 \\
1,718 & 2300 & 1,291 & 1,192 & 1,009 & 1,009 & 1,062 & 1,010 \\
1,793 & 2400 & 1,291 & 1,192 & 1,094 & 1,094 & 1,057 & 0,994 \\
1,868 & 2500 & 1,291 & 1,189 & 1,091 & 1,091 & 1,052 & 0,987 \\
\hline
\end{tabular}

Tabel 3. Hasil Nilai Rasio Konversi Setelah Perubahan Daya Linear

\begin{tabular}{lccccccc}
\hline \multirow{2}{*}{$\begin{array}{c}\text { Daya linear } \\
(\mathrm{MW} / \mathrm{cm})\end{array}$} & \multirow{2}{*}{$\begin{array}{c}\text { Daya } \\
(\mathrm{MW})\end{array}$} & \multicolumn{7}{c}{ Rasio konversi } \\
\cline { 3 - 8 } & & 1 & 2 & 3 & 4 & 5 & 6 \\
\hline 1,494 & 2000 & 0,489 & 0,516 & 0,534 & 0,568 & 0,599 & 0,653 \\
1,569 & 2100 & 0,489 & 0,516 & 0,536 & 5,721 & 0,604 & 0,660 \\
1,644 & 2200 & 0,489 & 0,517 & 0,537 & 0,576 & 0,608 & 0,671 \\
1,718 & 2300 & 0,489 & 0,517 & 0,539 & 0,579 & 0,614 & 0,679 \\
1,793 & 2400 & 0,489 & 0,518 & 0,541 & 0,583 & 0,619 & 0,684 \\
1,868 & 2500 & 0,489 & 0,519 & 0,542 & 0,587 & 0,624 & 0,692 \\
\hline
\end{tabular}

\subsection{Perubahan Fraksi Volume}

Perhitungan fraksi volume digunakan untuk menentukan persentase jumlah material seperti bahan bakar, kelongsong, dan moderator pada teras reaktor. Hasil dari perubahan fraksi volume tiap material ditunjukkan pada Tabel 4. Hasil nilai $k_{\text {eff }}$ dan rasio konversi dari perubahan fraksi volume berturut-turut ditunjukkan pada Tabel 5 dan Tabel 6.

Tabel 4. Fraksi Volume Tiap-Tiap Material Pada Teras Reaktor

\begin{tabular}{ccc}
\hline Komponen & Radius $(\mathrm{cm})$ & Fraksi Volume (\%) \\
\hline Bahan Bakar & 0,538300 & 52 \\
Selongsong & 0,595300 & 12 \\
Moderator & 0,746336 & 36 \\
\hline
\end{tabular}

Berdasarkan hasil pada Tabel 5 yang menghasilkan nilai $k_{\text {eff }}$ agar reaktor dapat menyala hingga akhir waktu operasi terjadi pada semua daya linear kecuali daya linear 1,868460 (daya reaktor sebesar $2500 \mathrm{MW}$ ) dengan nilai $k_{\text {eff }}$ sebesar 0,897209.

Berdasarkan hasil pada Tabel 6 menunjukkan bahwa nilai rasio konversi yang diperoleh hampir semua 1, hanya pada daya linear $1,494 \mathrm{MW} / \mathrm{cm}$ dan $1,569 \mathrm{MW} / \mathrm{cm}$ yang tidak menghasilkan 1 tetapi, jika dilihat dari nilai $k_{\text {eff }}$ yang diperoleh tidak semuanya akan menghasilkan reaktor yang dapat menyala hingga akhir waktu operasi. 
Ardanti W R, Yulianti Y, Riyanto A, dan Syafriadi, 2020. Perhitungan Burn Up pada Reaktor HCLWR Model Geometri Heksagonal Dua Dimensi BahanBakar Uranium menggunakan SRAC COREBN, Journal of Energy Material and Instrumentation Technology, Vol. 1 No. 1,2020

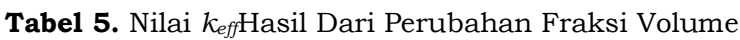

\begin{tabular}{|c|c|c|c|c|c|c|c|}
\hline \multirow{2}{*}{$\begin{array}{c}\text { Daya linear } \\
(\mathrm{MW} / \mathrm{cm})\end{array}$} & \multirow{2}{*}{$\begin{array}{l}\text { Daya } \\
\text { (Mw) }\end{array}$} & \multicolumn{6}{|c|}{ Faktor multiplikasi efektif $\left(k_{e f f}\right)$} \\
\hline & & 1 & 2 & 3 & 4 & 5 & 6 \\
\hline 1,494 & 2000 & 1,090 & 1,021 & 0,996 & 0,964 & 0,944 & 0,914 \\
\hline 1,569 & 2100 & 1,090 & 1,020 & 0,994 & 0,961 & 0,940 & 0,910 \\
\hline 1,644 & 2200 & 1,090 & 1,019 & 0,992 & 0,958 & 0,937 & 0,907 \\
\hline 1,718 & 2300 & 1,090 & 1,018 & 0,990 & 0,956 & 0,934 & 0,903 \\
\hline 1,793 & 2400 & 1,090 & 1,016 & 0,988 & 0,953 & 0,931 & 0,901 \\
\hline 1,868 & 2500 & 1,090 & 1,015 & 0,986 & 0,950 & 0,928 & 0,897 \\
\hline
\end{tabular}

Tabel 6. Nilai Rasio Konversi Hasil Dari Perubahan Fraksi Volume

\begin{tabular}{|c|c|c|c|c|c|c|c|}
\hline \multirow{2}{*}{$\begin{array}{l}\text { Daya linear } \\
(\mathrm{MW} / \mathrm{cm})\end{array}$} & \multirow{2}{*}{$\begin{array}{l}\text { Daya } \\
(\mathrm{Mw})\end{array}$} & \multicolumn{6}{|c|}{ Rasio konversi } \\
\hline & & 1 & 2 & 3 & 4 & 5 & 6 \\
\hline 1,494 & 2000 & 0,839 & 0,876 & 0,895 & 0,926 & 0,950 & 0,992 \\
\hline 1,569 & 2100 & 0,839 & 0,877 & 0,897 & 0,929 & 0,954 & 0,997 \\
\hline 1,644 & 2200 & 0,839 & 0,878 & 0,898 & 0,932 & 0,959 & 1,002 \\
\hline 1,718 & 2300 & 0,839 & 0,878 & 0,900 & 0,936 & 0,963 & 1,101 \\
\hline 1,793 & 2400 & 0,839 & 0,879 & 0,902 & 0,939 & 0,967 & 1,012 \\
\hline 1,868 & 2500 & 0,839 & 0,880 & 0,903 & 0,942 & 0,970 & 1.016 \\
\hline
\end{tabular}

Berdasarkan hasil penelitian yang telah dilakukan, perubahan yang signifikan untuk menghasilkan rasio konversi 1 yaitu ketika melakukan perubahan pada persentase bahan bakar (perubahan fraksi volume). Hal ini dikarenakan semakin kecil persentase bahan bakar yang digunakan akan mengakibatkan jumlah bahan bakar yang digunakan semakin banyak untuk proses pembakaran atau reaksi fisi (Nurkholiah dan Fitriyani, 2019). Persentase bahan bakar yang kecil akan membuat komposisi bahan fertil yang terdapat dalam reaktor juga sedikit, sehingga untuk menjaga kekritisan reaktor bahan bakar yang digunakan menjadi lebih banyak (Permata dan Handayani, 2016).

\section{Kesimpulan}

Berdasarkan hasil penelitian, analisis dan pembahasan diperoleh bahwa Semakin besar persentase pengayaan pada $\mathrm{U}^{235}$, maka nilai $k_{\text {eff }}$ akan semakin besar. Persentase yang optimal pada daerah satu dan tiga sebesar $3 \%$ sedang kan pada daerah dua $2,5 \%$. Periode burn up semakin lama, maka nilai $k_{\text {eff }}$ akan berkurang dan nilai rasio konversi akan bertambah. Pada periode burn up 548 hari reaktor tetap menyala hingga akhir periode. Semakin besar nilai daya linear, maka nilai $k_{\text {eff }}$ akan berkurang dan nilai rasio konversi bertambah. Hal ini dikarenakan berkurangnya nuklida fisil seiring bertambahnya burn up. Daya linear yang menghasilkan $k_{\text {eff }}$ dan rasiokonversi optimal yaitu1,792722 MW/cm. Fraksi volume yang dapat menghasilkan nilai rasio konversi 1 dengan $k_{\text {eff }}$ dapat membuat reactor menyala hingga akhir yaitu ketika persentase bahan bakar $52 \%$, kelongsong $12 \%$, dan moderator $36 \%$. Daya reaktor $2400 \mathrm{MW}$, dan daya linear $1,792722 \mathrm{MW} / \mathrm{cm}$.

\section{Daftar Pustaka}

Adiwardojo., Natio, L.A., Ruslan., Madi, P.E., dan Effendi, E. 2010. Mengenal Reaktor Nuklir dan Manfaatnya. Pusat Diseminasi Iptek Nuklir. Jakarta.

Agung, A. 2017. Diktat Kuliah: Analisis Reaktor Nuklir. UGM. Yogyakarta.

Antartika, A.P. 2017. Perhitungan Burn Up Model Assembly X-Y 2 Dimensi Pada SCWR Menggunakan Bahan Bakar Thorium. (Skripsi). Universitas Lampung. Lampung.

Ardiansyah, H., Agung, A., dan Widi, A.H. 2018. Studi Parameter Desain Teras Integral Pressurized Water Reactor dengan Bahan Bakar Mixed Oxide Fuel Menggunakan Program SRAC. Jurnal Forum Nuklir. Vol. 12. No. 2. Hal. 61-72.

Badan Tenaga Nuklir Indonesia (BATAN). Pengenalan Pembangkit Listrik Tenaga Nuklir. http://www.batan.go.id/index.php/id/infonuklir/pltn-infonuklir/generasi-pltn/924-pengenalanpembangkit-listrik-tenaga-nuklir. Di akses pada tanggal 19 Juni 2019. 
Ardanti dkk, 2020/ J. Energy Mater. Instrum. Technol. Vol. 1 No. 1, 2020

Bastori, Imam dan Moch Djoko Birmano. 2017. Analisis Ketersediaan Uranium di Indonesia untuk Kebutuhan PLTN Tipe PWR 1000 MWe. Jurnal Pengembangan Energi Nuklir. Vol. 19. No.2. Hal. 95-102.

Duderstadt, J.J dan Louis J.H. 1976. Nuclear Reactor Analysis. John Wiley and Sons, Inc. New York.

Ishiguro, Y. 1989. Development of High Conversion Light Water Reactor. Journal of Nuclear Science and Technology. Vol. 26. No. 1. Hal. 33-36.

Nurkholilah dan Fitriyani, D. 2019. Analisis Burn Up pada Reaktor Pembiak Cepat Berpendingin Pb-Bi dengan Variasi Fraksi Bahan Bakar dan Bahan Pendingin. Jurnal Fisika Unand. Vol. 8. No. 2. Hal. 184-190.

Nurul, M.S., Su'ud, Z., Waris, A., dan Permana, S. 2015. Studi Desain Reaktor Air Bertekanan (PWR) Berukuran Kecil Berumur Panjang Berbahan Bakar Thorium. Vol. 9. No. 1. Hal. 32-49.

Okumura,K. 2007. COREBN: A Core Burn-Up Calculation Module for SRAC2006. Reactor Physics Group, Nuclear Science and Engineering Directorate, Japan Atomic Energy Research Institute (JAERI). Tokaimura, Nakagun, Ibaraki-ken. Japan.

Permata, N.S., Fitriyani, D., dan Handayani, F.I. 2016. Analisis Neutronik Super Critical Water Reactor (SCWR) dengan Variasi Bahan Bakar (UN-PuN, UC-PuC, dan MOX). Jurnal Fisika Unand. Vol. 5. No. 1. Hal. 47-52

Subekhi, M. N., Suud, Z., Waris, Abdul., dan Permana, S. 2015. Studi Desain Air Bertekanan (PWR) Berukuran Kecil Berumur Panjang Berbahan Bakar Thorium. Vol. 9. No. 1. Hlm. $32-49 .$.

Sugimoto, J., Takamichi, I., Tsutomu, O., dan Yoshio, M. 1989. Thermal-Hydraulic Characteristic of Double Flat Core HCLWR. Tokai Research Establishment. Japan Atomic Energy Research Institute. 